\title{
Outcomes of implants placed after osteotome sinus floor elevation without bone grafts: a systematic review and meta- analysis of single-arm studies
}

\author{
Mingfu Ye* $e^{*}$, Wenjun Liu, Shaolong Cheng and Lihui Yan
}

\begin{abstract}
Background: The aim of this study is to evaluate the implant survival/success rate, gain in alveolar bone height, crestal bone loss, and complications associated with implants placed in the posterior maxilla after osteotome sinus floor elevation without bone substitutes.

Methods: The electronic databases, such as MEDLINE, EMBASE, CENTRAL, and SCOPUS were systematically and manually searched for publications in peer-reviewed journals. The included articles were subjected to qualitative and quantitative analyses, and the meta-analysis was carried out for single-arm studies. Methodological quality assessment was made for all the included studies.
\end{abstract}

Results: The included studies were of moderate quality, with the overall implant success and survival rates of 98.3\% and $97.9 \%$ respectively. The most frequent intra-surgical complication was sinus membrane perforation, accounting for 3.08\% of the total implants with reported perforations. The overall crestal bone loss in patients with immediate implants placed with OSFE after a 5 -year follow-up was $0.957 \mathrm{~mm} \mathrm{95 \% Cl}(0.538,1.377)$.

Conclusion: Within the limitations of this review, it can be concluded that the survival and success rates of implants placed immediately along with OSFE without any bone substitutes are acceptable and show adequate implant stability with less crestal bone loss over 5 years.

\section{Introduction}

Dental implants provide a strong foundation for fixed (permanent) or removable replacement teeth that are essential for the improvement of appearance, speech, eating, comfort, self-esteem, and oral health of the patients [1]. A loss of the natural dentition leads to a reduction of occlusal forces that activate a series of bone remodeling processes in the alveolar bone, causing pressure-threshold-regulated bone atrophy [1]. However, there is still not enough scientific evidence to determine

\footnotetext{
* Correspondence: Dentist_yipmyonphu@163.com

Department of Oral Implantology, Stomatological Hospital of Xiamen Medical College, Xiamen Key Laboratory of Stomatological Disease Diagnosis and Treatment, 1309, Lvling Road, Xiamen 361008, Fujian Province, People's
} Republic of China

\section{Springer Open}

whether osteoclastic bone resorption is pressure-thresholdregulated or proportionally pressure-dependent. Moreover, after tooth extraction, there is an increase in the osteoclastic activity of the periosteum of the maxillary sinus floor, leading to sinus maxillary sinus pneumatization and expansion into the alveolar bone crest [2]. Maxillary sinus pneumatization is a serious obstacle to oral implantology [2]. Therefore, there is a great need for specific surgical procedures to partially or totally reduce the expanded volume of this cavity. Several grafting techniques based on using autogenous bone (either alone, mixed with a bonesubstituting biomaterial, or biomaterial only) are now available. Insufficient alveolar bone height, width, and density, as well as quality and quantity of posterior edentulous maxillary bone, are common limiting factors for placement (c) The Author(s). 2021 Open Access This article is licensed under a Creative Commons Attribution 4.0 International License, which permits use, sharing, adaptation, distribution and reproduction in any medium or format, as long as you give appropriate credit to the original author(s) and the source, provide a link to the Creative Commons licence, and indicate if changes were made. The images or other third party material in this article are included in the article's Creative Commons licence, unless indicated otherwise in a credit line to the material. If material is not included in the article's Creative Commons licence and your intended use is not permitted by statutory regulation or exceeds the permitted use, you will need to obtain permission directly from the copyright holder. To view a copy of this licence, visit http://creativecommons.org/licenses/by/4.0/. 
of dental implants in the posterior maxillary region. These factors can increase incidences of implant failure and complications and worsen overall clinical outcomes of dental implant treatments [3]. Surgical sinus floor elevation (SFE) can significantly increase the height of bone available for implant placement. For dental implant placement, two main sinus floor elevation approaches can be used-direct and indirect. Direct SFE is a lateral window sinus grafting approach that is used for treating cases with a residual bone height of less than $5.0 \mathrm{~mm}$. This approach allows to increase bone height to $>5.0 \mathrm{~mm}$ but usually requires a 69-month delay in subsequent implant placement. Indirect SFE is a transalveolar approach that condenses bone grafting materials under the Schneiderian membrane in the presence of at least $5 \mathrm{~mm}$ of residual bone. This approach allows gaining approximately 3-5.0 $\mathrm{mm}$ of bone height within the sinus with a simultaneous implant placement [4].

The use of bone grafts for sinus augmentation, irrespective of the technique used, has been associated with a high success rate despite certain shortcomings, such as a need for a second surgical site for autogenous bone harvesting, increased rate of complications, higher cost, and increased surgical time. Lundgren et al. described spontaneous bone formation below the sinus floor after cyst enucleation, suggesting that proliferative and regenerative proprieties of the sinus membrane may have a potential for bone formation [5]. This concept led to a number of studies in which successful implant placement and rehabilitation were carried out without using bone grafts. These studies have demonstrated a guided tissue regeneration process, where bone deposition and new bone formation are induced by the blood clot in the void that is created after sinus augmentation [6].

In 2019, Rawat et al. conducted a prospective controlled clinical trial of 21 patients with 26 implants by indirect sinus lift with simultaneous implant placement without bone graft. This study demonstrated a predictable successful osseointegration with osteotome sinus floor elevation without bone graft, and spontaneous new bone formation [4]. A prospective study by Merheb et al. [7] compared the 5-year progression of implant stability in grafted and non-grafted sites in 12 patients with $\leq 4$ $\mathrm{mm}$ initial bone height in the posterior maxilla. The implants were positioned using osteotome sinus floor elevation. This study showed that the stability of implants positioned with osteotome sinus floor elevation in non-grafted sites is similar to that of implants placed in grafted sites. A randomized controlled trial by Qian et al. [8] evaluated long-term clinical and radiographic outcomes of implants placed using osteotome sinus floor elevation (OSFE) with or without bone grafting in 45 patients with $4.58 \pm 1.28 \mathrm{~mm}$ of average residual bone height. The study concluded that OSFE with or without grafting gives similar clinical outcomes with comparable alveolar bone gain. Since then several new studies have been published. The aim of the current study is to provide updated pooled evidence and meta-analysis by systematically searching the literature for all single-arm studies that evaluate the outcomes of implants placed in posterior maxillae after osteotome sinus floor elevation without bone substitutes.

\section{Methods \\ Review methodology}

This systematic review and meta-analysis of single-arm studies was carried out in strict accordance with Preferred Reporting Items for Systematic Review and Meta-Analyses (PRISMA) guidelines [9]. The protocol for smooth conduction of the systematic review was prepared a priori.

\section{Review question}

What is the survival/success rate of the implants placed in the posterior maxilla after osteotome sinus floor elevation without any bone substitutes?

What is the gain in alveolar bone height, crestal bone loss?

What intra-surgical and post-surgical complications were reported with the implants placed in the posterior maxilla after osteotome sinus floor elevation without any bone substitutes?

\section{Designing PICO}

The description of PICO is as follows:

\begin{tabular}{ll}
\hline $\begin{array}{l}\text { Population/type of } \\
\text { participants }\end{array}$ & $\begin{array}{l}\text { The patients indicated for immediate dental } \\
\text { implant placement in posterior maxillae with } \\
\text { insufficient residual bone height requiring sinus } \\
\text { elevation }\end{array}$ \\
Type of intervention & $\begin{array}{l}\text { Immediate dental implant placement following } \\
\text { osteotome sinus floor elevation without any } \\
\text { additional bone substitutes }\end{array}$ \\
Comparison & $\begin{array}{l}\text { Not applicable (single-arm studies) } \\
\text { Outcomes }\end{array}$ \\
& $\begin{array}{l}\text { Survival rate, success rate, gain in alveolar bone } \\
\text { height, crestal bone loss around implants, intra- } \\
\text { surgical and post-surgical complications }\end{array}$ \\
\hline
\end{tabular}

\section{Search strategy}

A comprehensive search was carried out in 4 electronic databases, MEDLINE, EMBASE, CENTRAL, and SCOPUS, using a series of relevant keywords: Maxillary sinus, Dental Implant, Sinus augmentation, Sinus elevation, Crestal sinus elevation, Summer's osteotome, Osteotome sinus floor elevation, OSFE, Indirect sinus lift, Immediate Implant, Survival rate. We searched each database from 1979 up to 10th February 2021. A manual search was also carried out in peer-reviewed international indexed journals, such as Clinical Implant Dentistry and 
Related Research, Clinical Oral Implant Research, Implant Dentistry, International Journal of Oral and Maxillofacial Implants, Journal of Clinical Periodontology, Journal of Periodontal and Implant Science, Journal of Periodontology, and Quintessence International, from inception till January 2021. The bibliographies of previously conducted relevant systematic reviews or randomized clinical trials were additionally screened for any potentially eligible articles. The search was limited to the studies published in the English language only.

Articles retrieved from the digitalized and manual sources were imported into a citation manager software to remove the duplicates, and the final set of retrieved studies was screened by looking at titles and abstracts on the basis of relevancy. The potentially eligible articles were then subjected to full text analysis.

\section{Selection of studies}

The study selection was carried out by two independent reviewers.

The inclusion criteria were as follows:

- Articles published in the English language

- Single-arm clinical studies with human subjects

- Articles employing OSFE alone without any bone substitute along with simultaneous placement of dental implant

- Articles with RBH measurements

- Articles with a minimum sample size of 10 and a minimum follow-up of 6 months-1 year

- Articles reporting implant survival/success rate, alveolar bone gain, crestal bone loss, or post-surgical adverse events

The articles not reporting the outcomes, or multiple publications with the same cohort, or employing ridge split or any additional augmentation procedures, were excluded.

\section{Data selection and extraction}

Data from the included articles were collected by two independent reviewers, and the information was entered into the excel sheet under the following domains: study design, sample size, gender, age range; smokers; number and location of implants placed; make, diameter, and length of implants placed; osteotome technique; followup months; etc. The primary outcomes assessed were implant survival, implant success, gain in alveolar bone height, and mean crestal bone loss around the implants placed. Secondary outcomes included the intra-surgical and post-surgical complications observed across the included studies. The authors were contacted through email for clarification and in case of any missing relevant information.

\section{Data synthesis}

The retrieved data was subjected to both qualitative and quantitative synthesis. Demographic and interventional characteristics were included in the table and summarized. In the case of two or more studies assessing similar outcomes, the quantitative items were subjected to single-arm pooled meta-analysis using the Open Meta-analyst 2.0 software. The pooled estimate of gain in alveolar bone height and mean crestal bone loss was expressed as mean and standard deviation with $95 \%$ confidence interval (CI). The dichotomous data pertaining to implant success/survival was expressed as pooled odd's ratio (OR) with 95\% CI. The heterogeneity among the included studies was assessed using $\mathrm{i}^{2}$ statistics. The $\mathrm{i}^{2}$ value greater than $70 \%$ was considered high heterogeneity, and less than $40 \%$ was considered low heterogeneity.

\section{Quality assessment}

The quality assessment of the included studies was carried out using the methodology assessment criteria adopted by Clementini et al., by judging the following domains: appropriateness in statistical analysis, validated measurements, reports of loss to follow-up, defined inclusion and exclusion criteria, and proper sample selection.

\section{Results}

A pool of 324 articles were retrieved from digitalized and manual searches and screened based on titles and abstracts. A total of 41 potentially eligible articles were selected for full text assessment. After evaluating inclusion and exclusion criteria, 35 articles $[4,7,8,10-41]$ were included, and 6 manuscripts [42-47] were excluded. The detailed study selection process is summarized in Fig. 1.

Seven clinical trials $[4,8,10,16,18,24,33]$, fifteen prospective clinical studies [7, 13-15, 17, 21, 22, 26-29, $31,32,37,39]$, twelve retrospective cohort studies [11, $12,19,20,23,25,30,34-36,40,41]$, and 1 case series [27] were included in this systematic review. The age of the patients included in the studies ranged from 17 to 90 years. Eight studies $[8,10,18,26,29,34,36,39]$ reported the inclusion of smokers, and two studies reported exclusion of smokers $[13,15]$. The rest of the studies did not report the smoking status of the patients. The follow-up period ranged between 6 months and 16 years. Overall, data on 2267 patients with a total of 3390 dental implants were reported in the 35 selected studies. The pre-operative residual bone height $(\mathrm{RBH})$ ranged from 2 to $13.5 \mathrm{~mm}$. The diameters of the implants varied between 3.3 and $7.0 \mathrm{~mm}$, and the length of the implants ranged from 6 to $15 \mathrm{~mm}$. The highest reported success rate was $100 \%$, and the lowest was $95 \%$. Demographic 


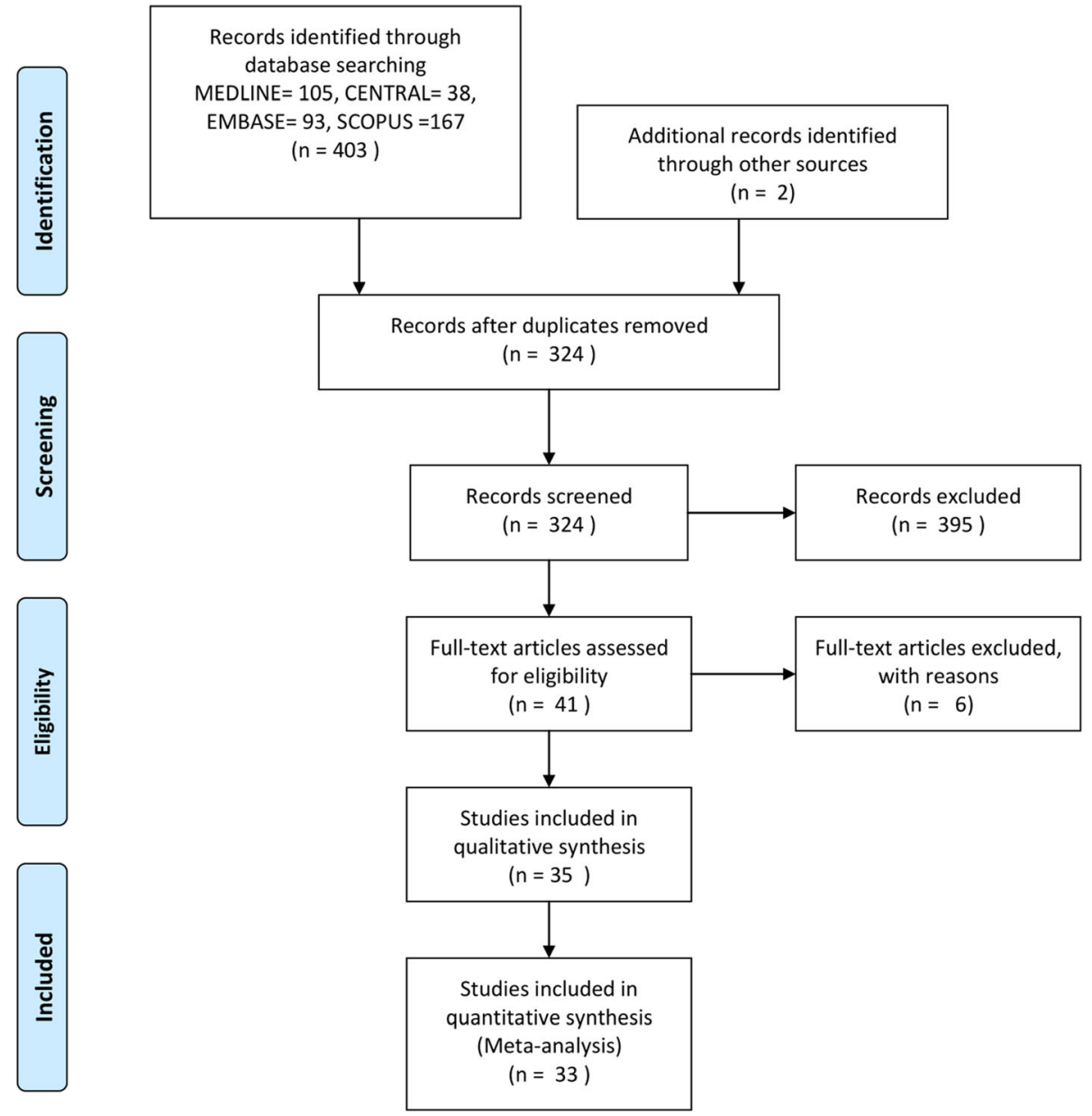

Fig. 1 Study selection process (PRISMA)

and interventional characteristics of the included studies are summarized in Table 1 and Table 2, respectively.

Intraoperative membrane perforation was the most frequently observed intraoperative complication and was reported by 22 studies [7, 10-17, 22, 24, 26-31, $33-35,37,39]$. Out of 22 studies, 11 studies [7, 17, 22, $24,26-29,34,35,37]$ did not report any tear or perforation in the sinus membrane. Membrane perforation occurred in 88 cases out of 2858 implants placed, accounting for $3.08 \%$ of the total implants with reported perforations. Postoperative nosebleed, paroxysmal vertigo, and infections were observed in few studies, however, they were less frequent. The details regarding the intra-surgical and post-surgical complications are provided in Table 3.

\section{Meta-analysis}

Fourteen different brands of implants were used; 5 articles $[10,12,25,28,41]$ did not report any information on the dental implant brands; 4 studies [10, 13, 17, 31] did not provide any information on the dental implant diameters.
The quantitative data retrieved from the parameters assessed in five included studies $[10,14,18,22,32]$ were pooled and the overall estimate with 95\% CI was obtained. Most of the studies used success criteria described by Buser et al. [48] and Albrektsson et al. [49].

The overall implant success rate was 98.3 (96.6100) \% (Fig. 2) with low heterogeneity (39.13\%). Pooled survival rate of the twenty-two included studies $[7,8,11-13,15,17,19,20,23-26,28-31,33-$ $36,39]$ was $97.9 \%(97.3,98.5)$ with $0 \%$ heterogeneity (Fig. 3).

The overall gain in the alveolar bone height was 2.459 $\mathrm{mm} 95 \% \mathrm{CI}(2.232,2.867)$ when the included studies describing $<6-\mathrm{mm}$ RBH were pooled (Fig. 4). For studies with $>6-\mathrm{mm} \mathrm{RBH}$, the overall gain was 2.218 $\mathrm{mm}, 95 \% \mathrm{CI}(1.882,2.554)$ (Fig. 5). The heterogeneity between the studies was high (94.71\%), possibly due to the variation in length of implants that ranged from 6 to $15 \mathrm{~mm}$ and the variability in the pre-operative RBH. The overall crestal bone loss in immediate implants placed 


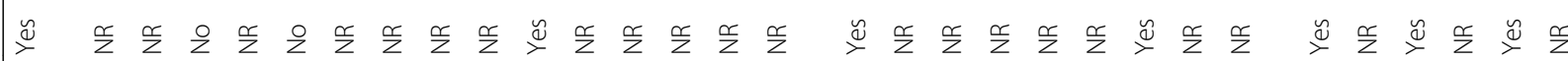

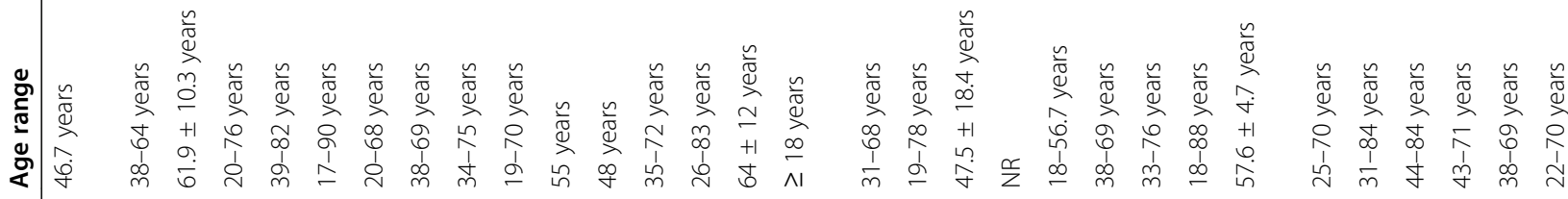

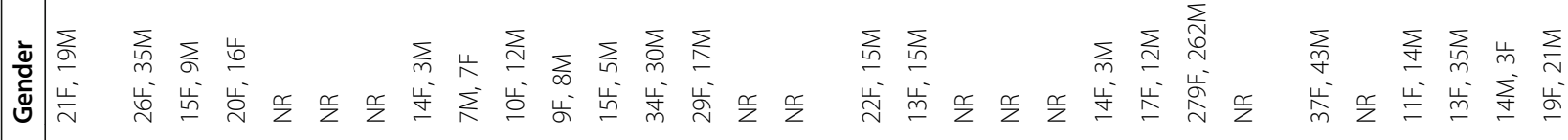

m d

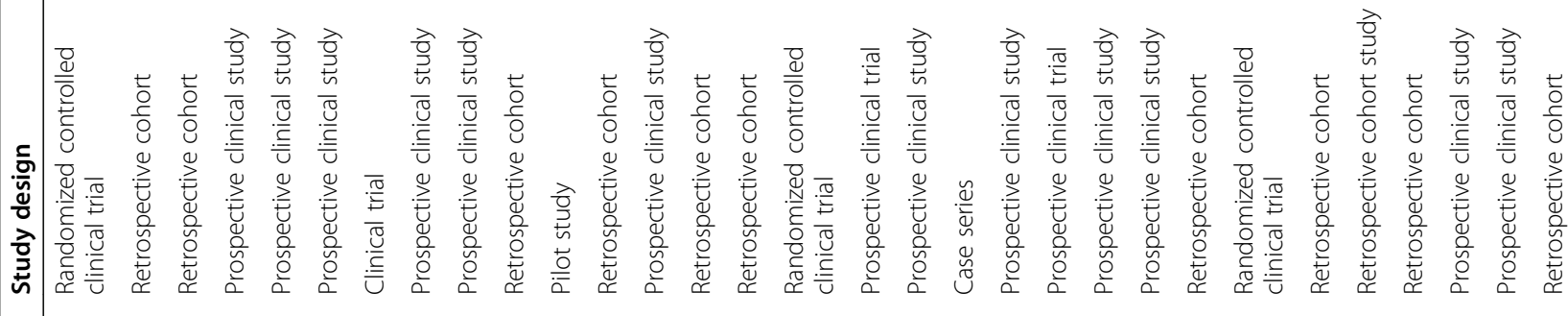

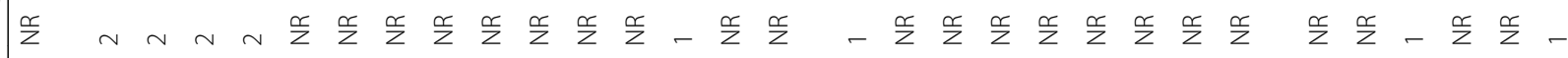

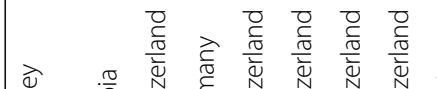

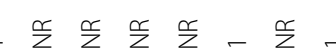
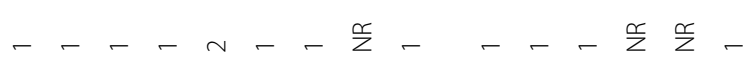

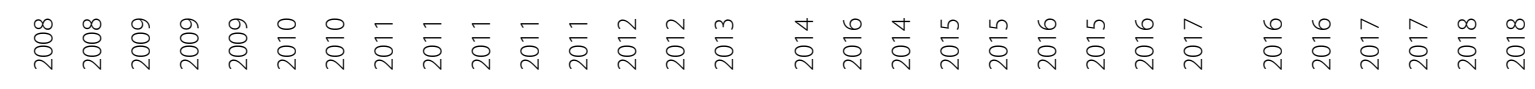

$\underset{\Xi}{\Xi} \stackrel{n}{\leftrightarrows}$

\section{$\infty \quad \stackrel{\square}{\infty}$}

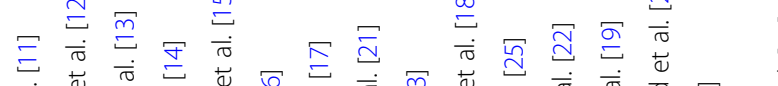

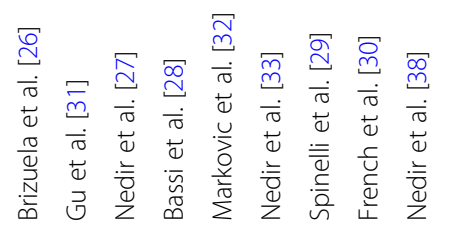

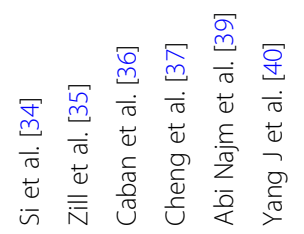

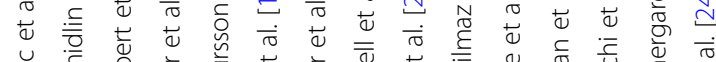

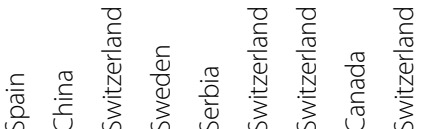

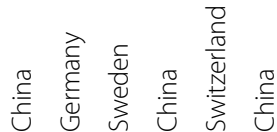

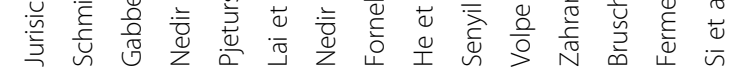




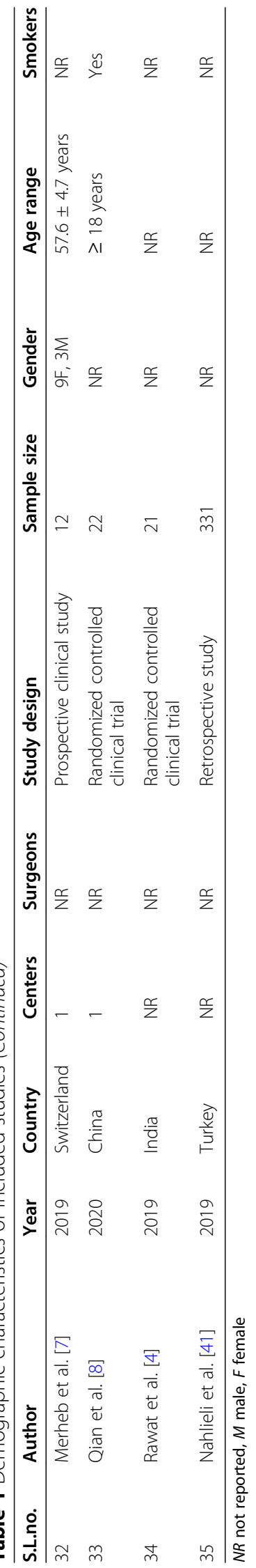




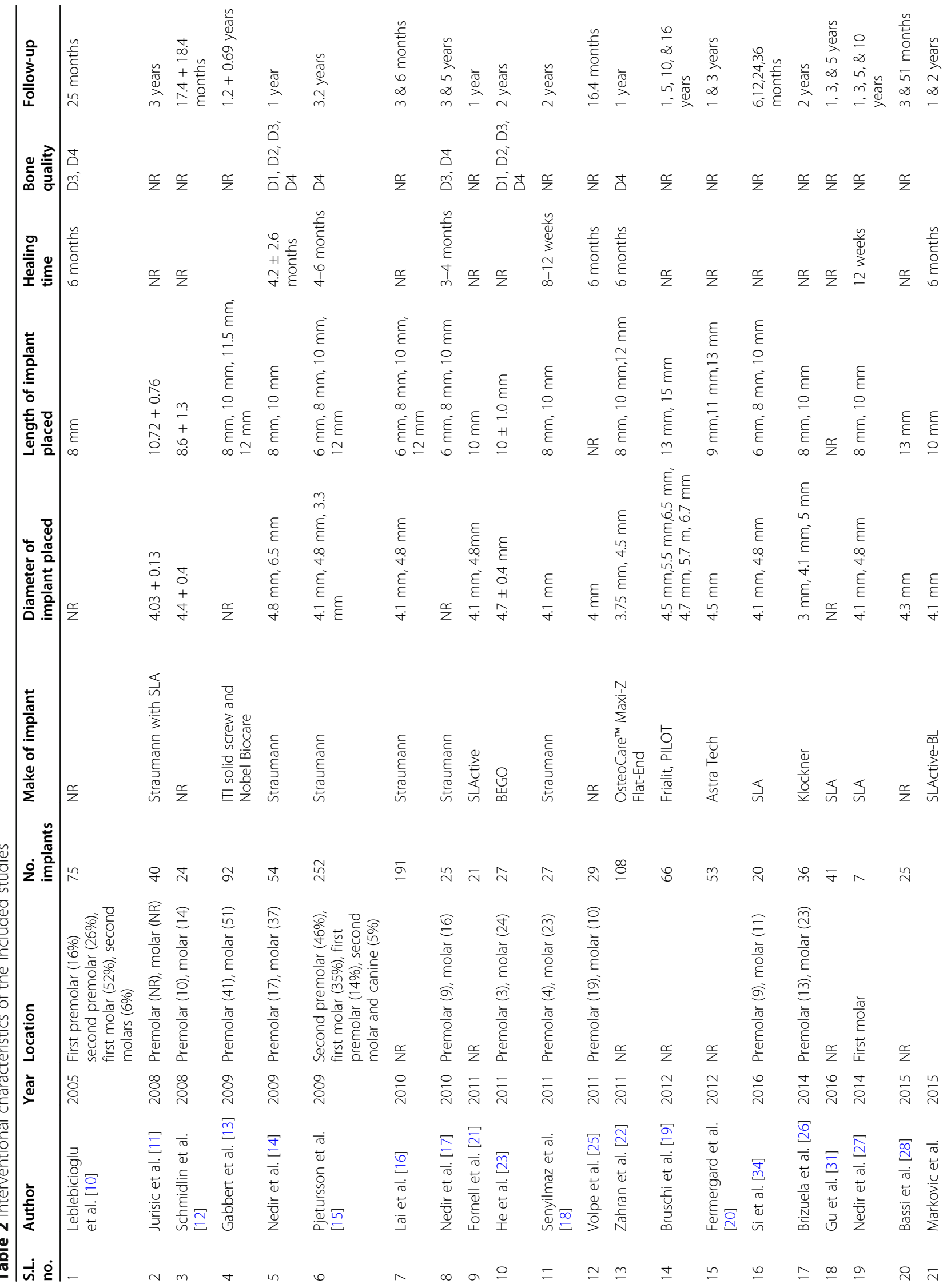




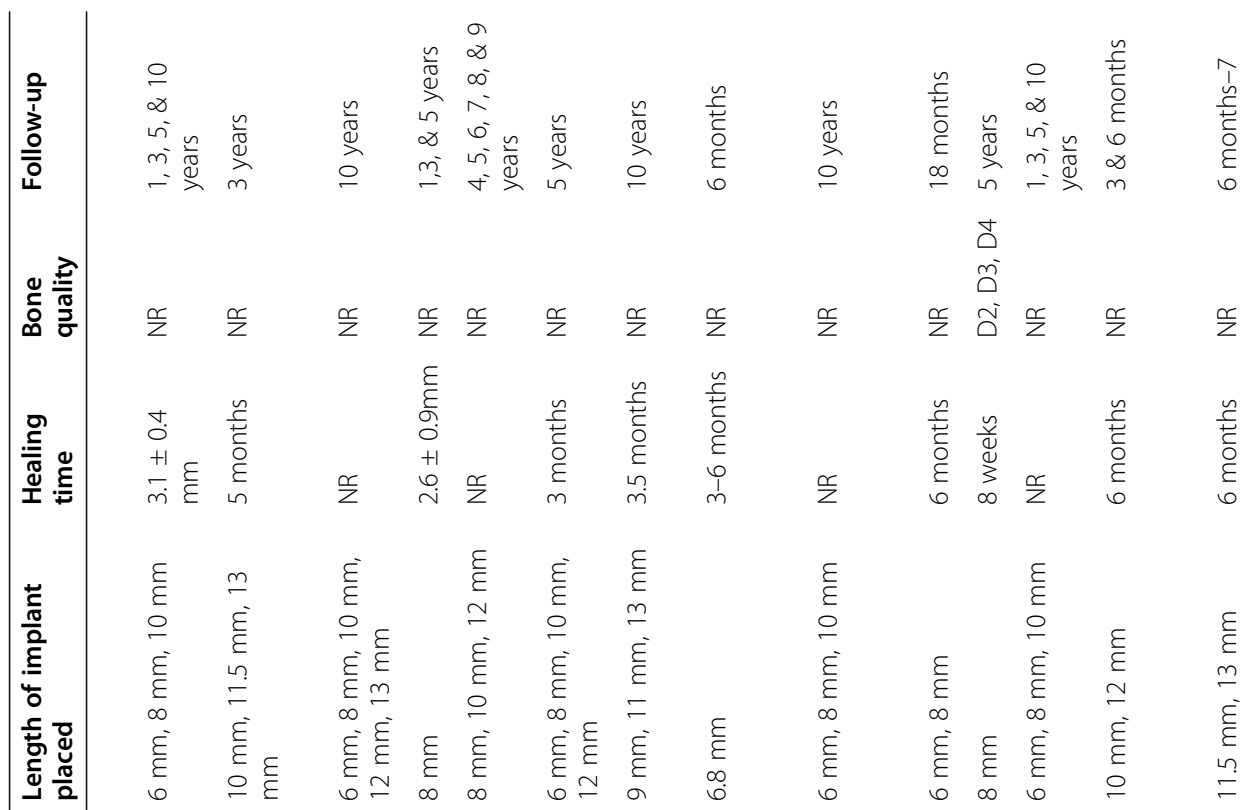

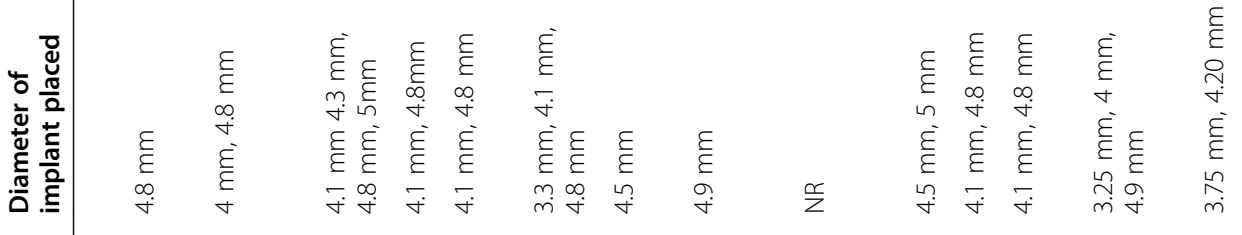

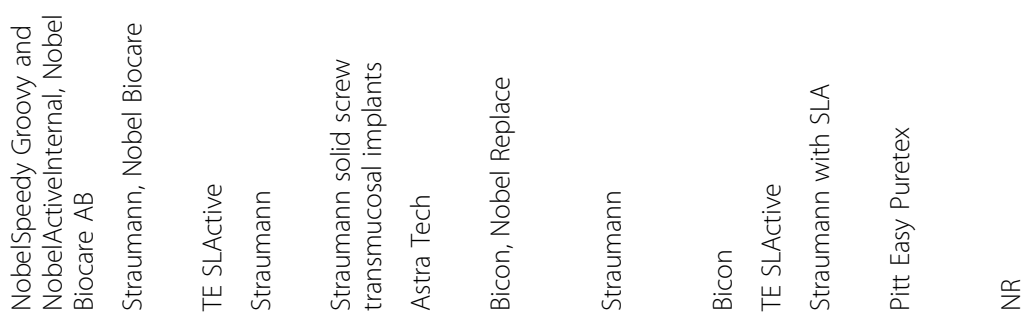


Table 3 Adverse events reported among the included studies

\begin{tabular}{|c|c|c|c|c|c|c|c|c|}
\hline S.L. no. & Author & Year & Sample size & $\begin{array}{l}\text { No. of } \\
\text { implants }\end{array}$ & $\begin{array}{l}\text { No. (\%) of } \\
\text { membrane } \\
\text { perforations }\end{array}$ & $\begin{array}{l}\text { Postoperative } \\
\text { nosebleed }\end{array}$ & $\begin{array}{l}\text { Postoperative } \\
\text { paroxysmal } \\
\text { vertigo }\end{array}$ & $\begin{array}{l}\text { Postoperative } \\
\text { infection }\end{array}$ \\
\hline 1 & Leblebicioglu et al. [10] & 2005 & 40 & 75 & $2(3.70)$ & 0 & $\mathrm{~N} / \mathrm{A}$ & 0 \\
\hline 2 & Jurisic et al. [11] & 2008 & 33 & 40 & 7 & N/A & N/A & 3 \\
\hline 3 & Schmidlin et al. [12] & 2008 & 24 & 24 & $2(8.33)$ & 1 & 0 & N/A \\
\hline 4 & Gabbert et al. [13] & 2009 & 36 & 92 & $24(26)$ & N/A & $\mathrm{N} / \mathrm{A}$ & 0 \\
\hline 5 & Nedir et al. [14] & 2009 & 32 & 54 & $5(9.25)$ & 0 & N/A & 0 \\
\hline 6 & Pjetursson et al. [15] & 2009 & 181 & 252 & $26(10.40)$ & N/A & 9 & 0 \\
\hline 7 & Lai et al. [16] & 2010 & 202 & 280 & $12(4.29)$ & 3 & 0 & 2 \\
\hline 8 & Nedir et al. [17] & 2010 & 17 & 25 & 0 & N/A & N/A & N/A \\
\hline 9 & Fornell et al. [21] & 2012 & 14 & 21 & $\mathrm{~N} / \mathrm{A}$ & N/A & $\mathrm{N} / \mathrm{A}$ & N/A \\
\hline 10 & He et al. [23] & 2013 & 22 & 27 & $\mathrm{~N} / \mathrm{A}$ & N/A & $\mathrm{N} / \mathrm{A}$ & N/A \\
\hline 11 & Senyilmaz et al. [18] & 2011 & 17 & 27 & N/A & N/A & N/A & N/A \\
\hline 12 & Volpe et al. [25] & 2013 & 20 & 29 & N/A & N/A & N/A & N/A \\
\hline 13 & Zahran et al. [22] & 2012 & 64 & 108 & 0 & 0 & N/A & 0 \\
\hline 14 & Bruschi et al. [19] & 2012 & 46 & 66 & $\mathrm{~N} / \mathrm{A}$ & 4 & N/A & N/A \\
\hline 15 & Fermergard et al. [20] & 2012 & 36 & 53 & $\mathrm{~N} / \mathrm{A}$ & N/A & $\mathrm{N} / \mathrm{A}$ & N/A \\
\hline 16 & Si et al. [24] & 2013 & 20 & 20 & 0 & 0 & N/A & 0 \\
\hline 17 & Brizuela et al. [26] & 2014 & 37 & 36 & 0 & 0 & N/A & 0 \\
\hline 18 & Gu et al. [31] & 2016 & 28 & 41 & 2 & 0 & N/A & 0 \\
\hline 19 & Nedir et al. [27] & 2014 & 7 & 7 & 0 & N/A & N/A & N/A \\
\hline 20 & Bassi et al. [28] & 2015 & 17 & 25 & 0 & 0 & $\mathrm{O}$ & 0 \\
\hline 21 & Nedir et al. [33] & 2016 & 17 & 25 & $4(16)$ & 1 & N/A & 0 \\
\hline 22 & Spinelli et al. [29] & 2015 & 39 & 66 & 0 & 0 & 0 & 0 \\
\hline 23 & French et al. [30] & 2016 & 541 & 926 & 1 & N/A & 0 & $1(0.1 \%)$ \\
\hline 24 & Nedir et al. [38] & 2017 & 9 & 17 & N/A & N/A & 0 & 1 \\
\hline 25 & Si et al. [34] & 2016 & 80 & 96 & 0 & 0 & N/A & 0 \\
\hline 26 & Zill et al. [35] & 2016 & 113 & 233 & 0 & N/A & $\mathrm{N} / \mathrm{A}$ & N/A \\
\hline 27 & Caban et al. [36] & 2017 & 25 & 34 & N/A & N/A & N/A & 0 \\
\hline 28 & Cheng et al. [37] & 2017 & 29 & 48 & 0 & 0 & N/A & 0 \\
\hline 29 & Abi Najm et al. [39] & 2018 & 17 & 21 & 3 & N/A & N/A & 1 \\
\hline 30 & Yang J et al. [40] & 2018 & 40 & 27 & $\mathrm{~N} / \mathrm{A}$ & N/A & N/A & N/A \\
\hline 31 & Merheb et al. [7] & 2020 & 12 & 20 & 0 & N/A & $\mathrm{N} / \mathrm{A}$ & 0 \\
\hline 32 & Qian et al. [8] & 2020 & 22 & 22 & $\mathrm{~N} / \mathrm{A}$ & N/A & N/A & 0 \\
\hline 33 & Rawat et al. [4] & 2019 & 21 & 26 & N/A & N/A & N/A & N/A \\
\hline
\end{tabular}

N/A data not available

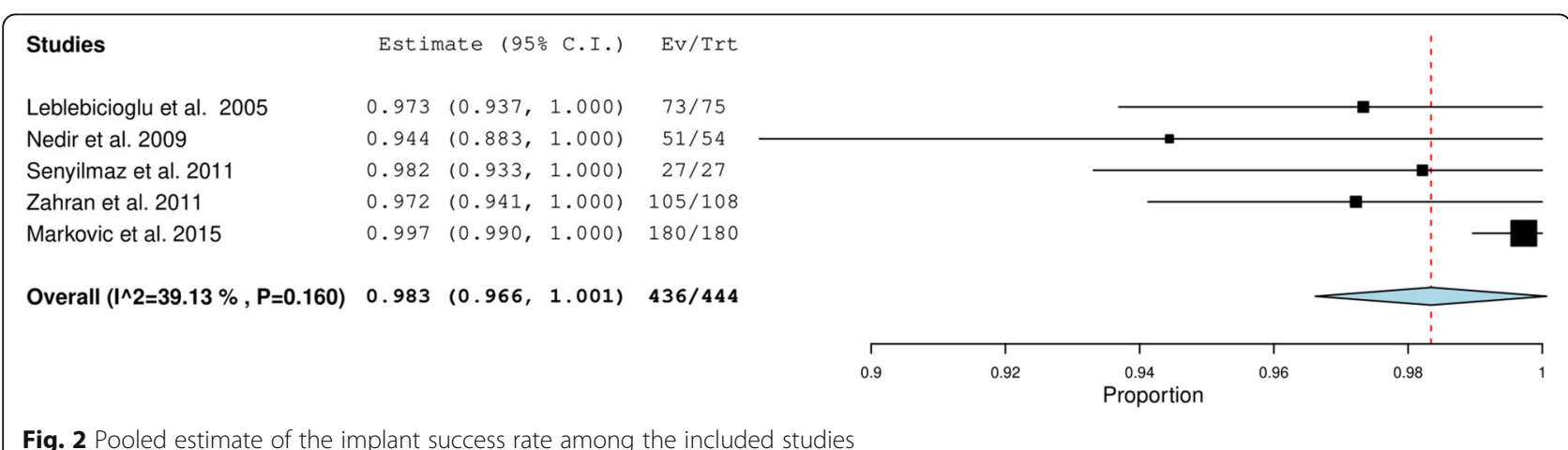


Studies

Jurisic et al. 2008

Schmidlin et al. 2008

Gabbert et al. 2009

Pjertursson et al. 2009

Nedir et al. 2010

He et al. 2011

Volpe et al. 2011

Bruschi et al. 2010

Fermergard et al. 2012

Si et al. 2013

Brizuela et al. 2014

Gu et al. 2014

Bassi et al. 2015

Nedir et al 2015

Spinelli et al. 2015

French et al. 2016

Si et al 2016

Zill et al. 2016

Caban et al. 2017

Abi Najm et al. 2018

Merheb et al. 2020

Qian et al. 2020

Overall (|^2=0\%,P=0.606) $0.979(0.973,0.985) \quad 2069 / 212$
Estimate (95\% C.I.) Ev/Trt

$0.988(0.954,1.000) \quad 40 / 40$

$0.980(0.925,1.000) \quad 24 / 24$

$0.957(0.915,0.998) \quad 88 / 92$

$0.976(0.957,0.995)$

$0.981(0.928,1.000) \quad 25 / 25$

$0.982(0.933,1.000) \quad 27 / 27$

$0.983(0.938,1.000) \quad 29 / 29$

$0.924(0.860,0.988)$

$0.991(0.965,1.000) \quad 53 / 53$

$0.889(0.786,0.992)$

$0.946(0.073,1.000)$

$.981(0.928,1.000) \quad 25 / 25$

$0.985(0.955,1.000) \quad 65 / 66$

$0.983(0.974,0.991) \quad 910 / 926$

$0.906(0.848,0.965)=87 / 96$

$0.95910 .929,0.9891$

$0.986(0.949,1.000) \quad 36 / 36$

$0.977(0.915,1.000) \quad 21 / 21$

$0.972(0.896,1.000) \quad 17 / 17$

$0.956(0.895,1.000) \quad 43 / 4$
$0.979(0.922,1.000) \quad 23 / 23$

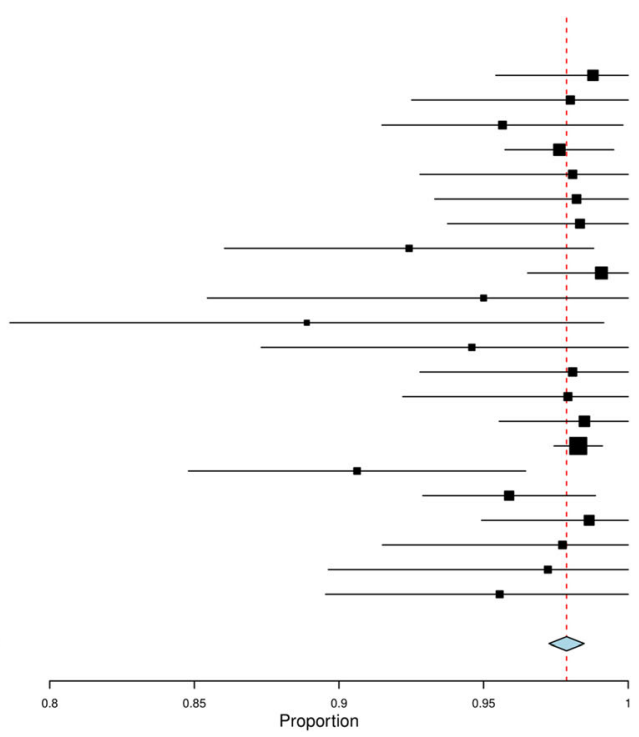

Fig. 3 Pooled estimate of the implant survival rate among the included studies

with OSFE after a 5-year follow-up was $0.957 \mathrm{~mm}$, $95 \% \mathrm{CI}(0.538,1.377)$ (Fig. 6).

The quality of the included studies was moderate. One of the included studies [27] was a case series study, with a high risk in sample selection. However, most of the studies were ranked at low to moderate risk for appropriateness in statistical analysis, validated measurements, report of loss to follow-up, defined inclusion and exclusion criteria, and proper sample selection. The methodological quality assessment summary of included studies is provided in Fig. 7.

\section{Discussion}

This systematic review and meta-analysis included 35 studies with a total of 3390 dental implants in 2267 patients.

The included studies reported both implant success and implant survival rates. The implant success rate is determined according to predefined success criteria [50]. The included studies reporting success rates employed one of the two success criteria described by Alberktson et al. [49], and Buser et al. [48], respectively. One included study [15] used different success criteria based on the clinical and radiological parameters such as distance between implant shoulder and mucosal margin, probing pocket depth, attachment level, and marginal bone level. The study was therefore not included in the pooled estimation of implant success rate. The overall implant success was estimated in only five out of 35 studies, showing a rate of $98.3 \%$. The implant survival rate refers to the number of implants remaining in the patient's mouth until the end of the follow-up period. The overall estimate of implant survival in our study was $97.9 \%$.

The implant success/survival can be influenced by numerous factors, implant dimension, surface characteristics,

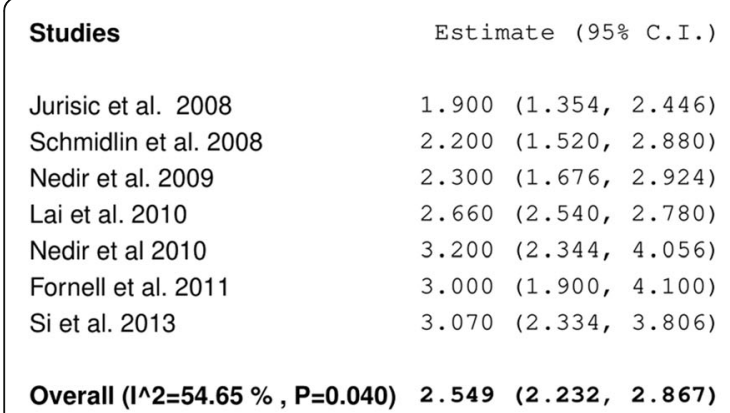

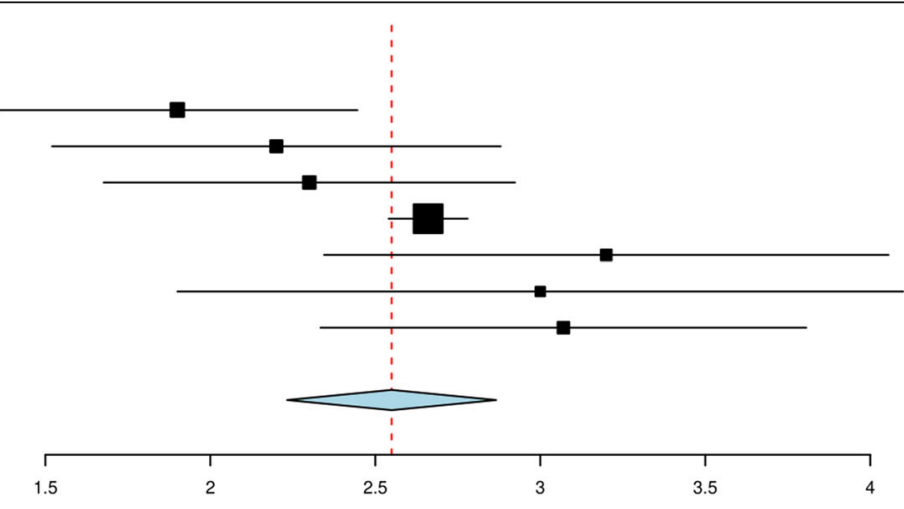

Fig. 4 Pooled estimate of gain in alveolar bone height with RBH less than $6 \mathrm{~mm}$ 


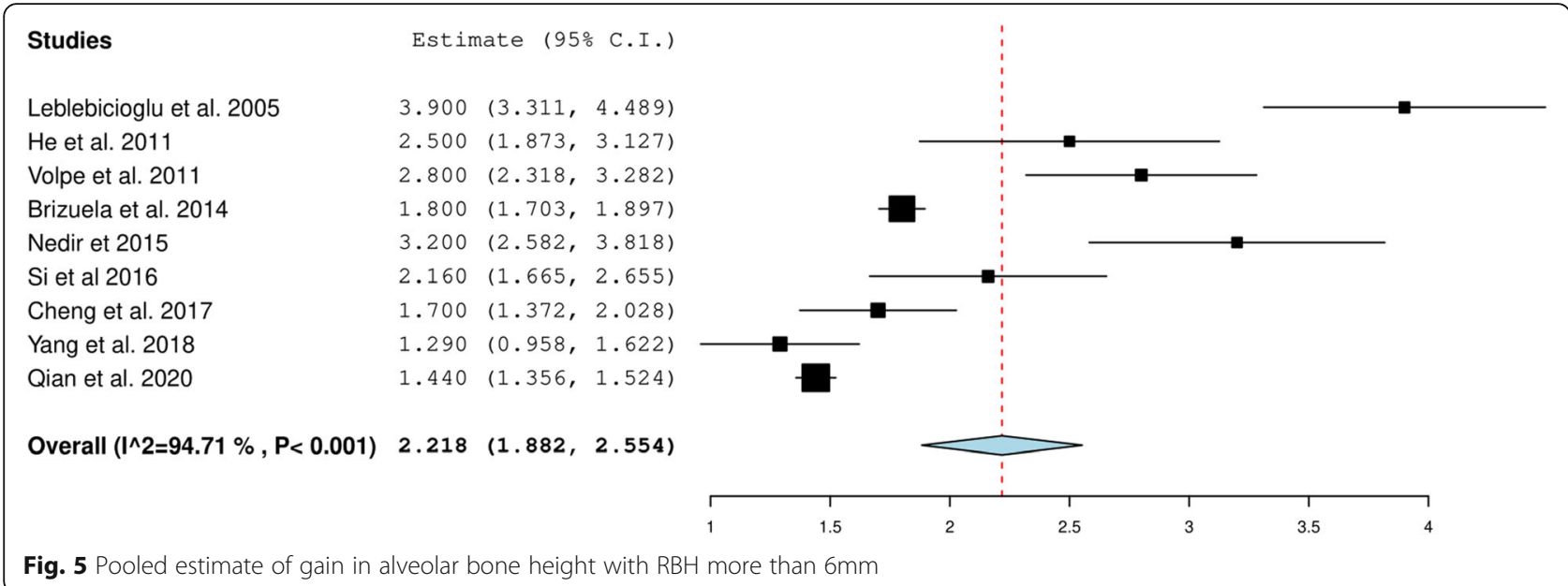

host factors, surgical technique, or any postoperative complications or infections [51]. The implant length reported in the included articles ranged from $6,8,10,11.5$, 13 , and $15 \mathrm{~mm}$. Majority of included studies reported length between 8 and $13 \mathrm{~mm}$. Only 9 studies [8, 15-17, 30, $33-35,39]$ used $6-\mathrm{mm}$ length implants. One of the included articles [15] assessed the success rate relative to the length of the implant placed. According to Pjetursson et al. [15], the success rate of 6-mm transalveolar short implants placed with OSFE was $47.6 \%$, while 8,10 , and $12-\mathrm{mm}$ implants had success rates of $88.7 \%, 88.8 \%$, and $100 \%$ respectively. The use of short implants resulted in reduced success/survival rate over a period of time. However, at the same time, it could reduce the chances of membrane tears.

The most common and frequent diameter of implants among the included studies ranged between 4 and 5 $\mathrm{mm}$. However, only one study assessed implant survival in relation to the different implant diameters [16]. Lai et al. [16] showed that 161 implants with a diameter of $4.1 \mathrm{~mm}$ had a $95.15 \%$ survival rate, while 115 implants with a diameter of $4.8 \mathrm{~mm}$ had a survival rate of $96.62 \%$ [16].

Implant type as well as its surface characterization could also affect the implant success/survival rate. Sand- blasted, large-grit, acid-etched threaded implants were one of the most common types of implants used in the included articles. The SLA-treated surface results in increased bone-to-implant contact due to the elevated level of osteoblast proliferation and cellular adhesion at the surface of the dental implant [52]. These factors play a significant role in the process of osseointegration and aid in improving the wettability of the implant which is essential for better osseointegration in closed spaces like sinuses filled with blood clots.

The most frequent intra-surgical complication reported in the included studies was sinus membrane perforation, which occurred in 88 cases out of 2858 implants placed, $3.08 \%$ of the total implants with reported perforations. These results are in agreement with a previous systematic review by Tan et al. [53] that reported a total of $3.8 \%$ of perforations among 1776 implants assessed. A study by Del Fabbro et al. [54] also revealed $4.2 \%$ perforations out of a total of 3131 implants.

The endo-sinus bone gain is relative to the length of the implant [55]. Our analysis showed that the overall gain in the alveolar bone height was relatively higher in studies with $<6-\mathrm{mm} \mathrm{RBH}$ than in studies with $>6-\mathrm{mm}$ $\mathrm{RBH}(2.459 \mathrm{~mm} 95 \% \mathrm{CI}(2.232,2.867)$ as compared to $2.218 \mathrm{~mm}$ 95\% CI (1.882, 2.554)). The heterogeneity

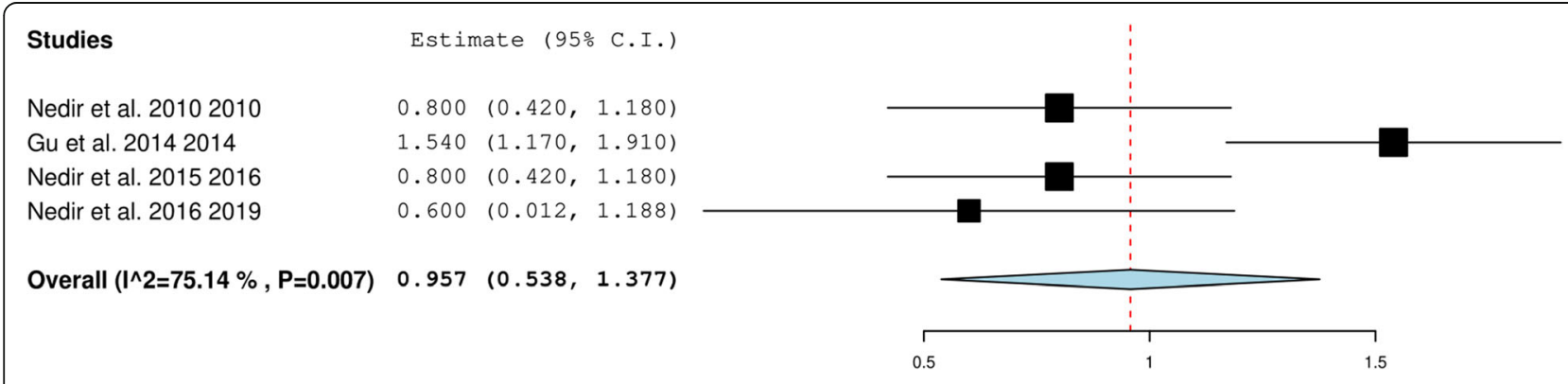

Fig. 6 Pooled estimate of crestal bone loss in immediate implants placed with OSFE after a 5-year follow-up 


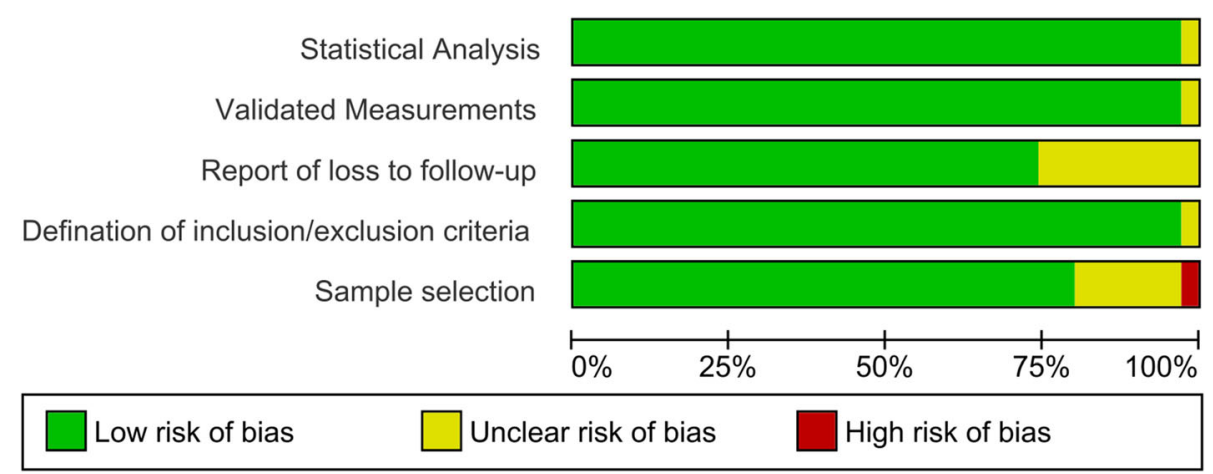

Fig. 7 Methodological quality assessment of included studies

among the included studies was high, probably due to possible confounding factors, such as the different lengths of the dental implants, RBH ranging from 2.1 to $6 \mathrm{~mm}$, and inclusion of smokers among the participants. Smoking could be a detrimental factor leading to implant failure. A study by Barone et al. [56] concluded that the postoperative infection rate was higher in smokers compared to non-smokers. This was further supported by the observation by Cha et al. [57] that smoking could be a possible factor of implant failure in immediate implants placed after OSFE. In the present systematic review, the included studies were heterogeneous, and the effect of smoking on any of the parameters could not be assessed.

A prospective randomized controlled trial by Nedir et al. 2017 [38] showed that the mean crestal bone loss at the end of 5 years was $0.6+1.1 \mathrm{~mm}$. The overall crestal bone loss in immediate implants placed with OSFE after a 5-year follow-up was $0.957 \mathrm{~mm} \mathrm{95 \% CI}$ $(0.538,1.377)$. The crestal bone loss around implants is observed at a higher rate in the first year of functional loading. After that, the marginal bone remains relatively stable in well-placed, properly osseo-integrated implants.

\section{Conclusion}

Within the limitations of this review, it can be concluded that the survival and success rates of implants placed immediately along with OSFE without any bone substitutes are 97.9 and $98.3 \%$, respectively. The most common complication observed with this technique was membrane perforation (up to $3.07 \%$ of the cases) that did not affect the survival of implants. OSFE showed improved alveolar bone height in the posterior maxilla with $\mathrm{RBH}<6 \mathrm{~mm}$ and relatively stable crestal bone loss at the end of a 5 -year follow-up.

\section{Authors' contributions}

MY designed the project; WL, SC, and LY were involved in data collection and data analysis; MY prepared and edited the manuscript; all authors read and approved the final manuscript.

Funding

None

Availability of data and materials

The datasets used and/or analyzed during the current study are available from the corresponding author on reasonable request.

\section{Declarations}

Ethics approval and consent to participate

Not applicable.

\section{Consent for publication}

Not applicable.

\section{Competing interests}

Mingfu Ye, Wenjun Liu, Shaolong Cheng, and Lihui Yan declare that they have no competing interests.

Received: 17 March 2021 Accepted: 13 May 2021

Published online: 09 August 2021

\section{References}

1. Sato T, Hara T, Mori S, Shirai H, Minagi S. Threshold for bone resorption induced by continuous and intermittent pressure in the rat hard palate. J Dent Res. 1998;77(2):387-92. https://doi.org/10.1177/ 00220345980770020701.

2. Chanavaz M. Maxillary sinus: anatomy, physiology, surgery, and bone grafting related to implantology--eleven years of surgical experience (19791990). J Oral Implantol. 1990:16(3):199-209.

3. Esposito M, Grusovin MG, Rees J, Karasoulos D, Felice P, Alissa R, et al. Effectiveness of sinus lift procedures for dental implant rehabilitation: a Cochrane systematic review. Eur J Oral Implantol. 2010;3(1):7-26.

4. Rawat A, Thukral $H$, Jose A. Indirect sinus floor elevation technique with simultaneous implant placement without using bone grafts. Ann Maxillofac Surg. 2019:9(1):96-102. https://doi.org/10.4103/ams.ams_11_19.

5. Lundgren S, Andersson S, Sennerby L. Spontaneous bone formation in the maxillary sinus after removal of a cyst: coincidence or consequence? Clin Implant Dent Relat Res. 2003;5(2):78-81. https://doi.org/10.1111/j.1708-82 08.2003.tb00187.x.

6. Moon J-W, Sohn D-S, Heo J-U, Shin H-I, Jung J-K. New bone formation in the maxillary sinus using peripheral venous blood alone. J Oral Maxillofac Surg Off J Am Assoc Oral Maxillofac Surg. 2011;69(9):2357-67. https://doi. org/10.1016/j.joms.2011.02.092.

7. Merheb J, Nurdin N, Bischof M, Gimeno-Rico M, Quirynen M, Nedir R. Stability evaluation of implants placed in the atrophic maxilla using 
osteotome sinus floor elevation with and without bone grafting: a 5-year prospective study. Int J Oral Implantol Berl Ger. 2019;12:337-46.

8. Qian S-J, Mo J-J, Si M-S, Qiao S-C, Shi J-Y, Lai H-C. Long-term outcomes of osteotome sinus floor elevation with or without bone grafting: the 10-year results of a randomized controlled trial. J Clin Periodontol. 2020;47(8):101625. https://doi.org/10.1111/jcpe.13260.

9. Liberati A, Altman DG, Tetzlaff J, Mulrow C, Gøtzsche PC, loannidis JPA, et al. The PRISMA statement for reporting systematic reviews and meta-analyses of studies that evaluate health care interventions: explanation and elaboration. J Clin Epidemiol. 2009;62(10):e1-34. https://doi.org/10.1016/j. jclinepi.2009.06.006.

10. Leblebicioglu B, Ersanli S, Karabuda C, Tosun T, Gokdeniz H. Radiographic evaluation of dental implants placed using an osteotome technique. J Periodontol. 2005;76(3):385-90. https://doi.org/10.1902/jop.2005.76.3.385.

11. Jurisic M, Markovic A, Radulovic M, Brkovic BMB, Sándor GKB. Maxillary sinus floor augmentation: comparing osteotome with lateral window immediate and delayed implant placements. An interim report. Oral Surg Oral Med Oral Pathol Oral Radiol Endod. 2008;106(6):820-7. https://doi.org/10.1016/j. tripleo.2008.04.025.

12. Schmidlin PR, Müller J, Bindl A, Imfeld H. Sinus floor elevation using an osteotome technique without grafting materials or membranes. Int J Periodontics Restorative Dent. 2008;28(4):401-9.

13. Gabbert O, Koob A, Schmitter M, Rammelsberg P. Implants placed in combination with an internal sinus lift without graft material: an analysis of short-term failure. J Clin Periodontol. 2009;36(2):177-83. https://doi.org/1 0.1111/j.1600-051X.2008.01357.x.

14. Nedir R, Nurdin N, Szmukler-Moncler S, Bischof M. Osteotome sinus floor elevation technique without grafting material and immediate implant placement in atrophic posterior maxilla: report of 2 cases. J Oral Maxillofac Surg Off J Am Assoc Oral Maxillofac Surg. 2009;67(5):1098-103. https://doi. org/10.1016/j.joms.2008.12.013.

15. Pjetursson BE, Rast C, Brägger U, Schmidlin K, Zwahlen M, Lang NP. Maxillary sinus floor elevation using the (transalveolar) osteotome technique with or without grafting material. Part I: implant survival and patients' perception. Clin Oral Implants Res. 2009;20(7):667-76. https://doi.org/1 0.1111/j.1600-0501.2009.01704.x.

16. Lai H-C, Zhuang L-F, Lv X-F, Zhang Z-Y, Zhang Y-X, Zhang Z-Y. Osteotome sinus floor elevation with or without grafting: a preliminary clinical trial. Clin Oral Implants Res. 2010;21(5):520-6. https://doi.org/1 0.1111/j.1600-0501.2009.01889.x.

17. Nedir R, Nurdin N, Vazquez L, Szmukler-Moncler S, Bischof M, Bernard J-P. Osteotome sinus floor elevation technique without grafting: a 5-year prospective study. J Clin Periodontol. 2010;37(11):1023-8. https://doi.org/1 0.1111/j.1600-051X.2010.01610.x.

18. Senyilmaz DP, Kasaboglu O. Osteotome sinus floor elevation without bone grafting and simultaneous implant placement in the atrophic maxilla: a pilot study. Indian J Dent Res Off Publ Indian Soc Dent Res. 2011;22(6):7869. https://doi.org/10.4103/0970-9290.94669.

19. Bruschi GB, Crespi R, Capparè $P$, Gherlone E. Transcrestal sinus floor elevation: a retrospective study of 46 patients up to 16 years. Clin Implant Dent Relat Res. 2012;14(5):759-67. https:/doi.org/10.1111/j.1708-8208.2010.00313.x.

20. Fermergård R, Åstrand P. Osteotome sinus floor elevation without bone grafts--a 3-year retrospective study with Astra tech implants. Clin Implant Dent Relat Res. 2012;14(2):198-205. https://doi.org/10.1111/j.1 708-8208.2009.00254.x

21. Fornell J, Johansson L- $\AA$, Bolin A, Isaksson S, Sennerby L. Flapless, CBCTguided osteotome sinus floor elevation with simultaneous implant installation. I: radiographic examination and surgical technique. A prospective 1-year follow-up. Clin Oral Implants Res. 2012;23(1):28-34. https://doi.org/10.1111/j.1600-0501.2010.02151.x.

22. Zahran A, Mostafa B, Reda A. Evaluation of flapless osteotomemediated sinus floor elevation with simultaneous implant placement. 2012. undefined [Internet]. [cited 2021 Mar 15]; Available from: https:/osteocare.uk.com/wp-content/uploa ds/2020/01/Evaluation-of-Flapless-Osteotome-Mediated-Sinus-Floor-Elevationwith-Simultaneous-Implant-Placement-Amr-Zahran-Basma-Mostafa-.pdf.

23. He L, Chang $X$, Liu Y. Sinus floor elevation using osteotome technique without grafting materials: a 2-year retrospective study. Clin Oral Implants Res. 2013;24 Suppl A100:63-7.

24. Si M, Zhuang L, Gu Y, Mo J, Qiao S, Lai H. Osteotome sinus floor elevation with or without grafting: a 3-year randomized controlled clinical trial. J Clin Periodontol. 2013;40(4):396-403. https://doi.org/10.1111/jcpe.12066.
25. Volpe S, Lanza M, Verrocchi D, Sennerby L. Clinical outcomes of an osteotome technique and simultaneous placement of Neoss implants in the posterior maxilla. Clin Implant Dent Relat Res. 2013;15(1):22-8. https:// doi.org/10.1111/j.1708-8208.2011.00378.x.

26. Brizuela A, Martín N, Fernández-Gonzalez FJ, Larrazábal C, Anta A. Osteotome sinus floor elevation without grafting material: results of a 2-year prospective study. J Clin Exp Dent. 2014;6(5):e479-84. https://doi.org/10.431 7/jced.51576.

27. Nedir R, Nurdin N, El Hage M, Bischof M. Osteotome sinus floor elevation procedure for first molar single-gap implant rehabilitation: a case series. Implant Dent. 2014;23(6):760-7. https://doi.org/10.1097/ID. 0000000000000177

28. Bassi APF, Pioto R, Faverani LP, Canestraro D, Fontão FGK. Maxillary sinus lift without grafting, and simultaneous implant placement: a prospective clinical study with a 51-month follow-up. Int J Oral Maxillofac Surg. 2015; 44(7):902-7. https://doi.org/10.1016/j.jom.2015.03.016.

29. Spinelli D, DE Vico G, Condò R, Ottria L, Arcuri C. Transcrestal guided sinus lift without grafting materials: a 36 months clinical prospective study. Oral Implantol. 2015;8(2-3):74-86. https://doi.org/10.11138/orl/2015.8.2.074.

30. French D, Nadji N, Shariati B, Hatzimanolakis P, Larjava H. Survival and success rates of dental implants placed using osteotome sinus floor elevation without added bone grafting: a retrospective study with a followup of up to 10 years. Int J Periodontics Restorative Dent. 2016;36(Suppl): s89-97. https://doi.org/10.11607/prd.2191.

31. Gu Y-X, Shi J-Y, Zhuang L-F, Qian S-J, Mo J-J, Lai H-C. Transalveolar sinus floor elevation using osteotomes without grafting in severely atrophic maxilla: a 5-year prospective study. Clin Oral Implants Res. 2016;27(1):120-5. https://doi.org/10.1111/clr.12547.

32. Marković A, Mišić T, Calvo-Guirado JL, Delgado-Ruíz RA, Janjić B, Abboud M. Two-center prospective, randomized, clinical, and radiographic study comparing osteotome sinus floor elevation with or without bone graft and simultaneous implant placement. Clin Implant Dent Relat Res. 2016;18(5): 873-82. https://doi.org/10.1111/cid.12373.

33. Nedir R, Nurdin N, Vazquez L, Abi Najm S, Bischof M. Osteotome sinus floor elevation without grafting: a 10-year prospective study. Clin Implant Dent Relat Res. 2016;18(3):609-17. https://doi.org/10.1111/cid.12331.

34. Si M-S, Shou Y-W, Shi Y-T, Yang G-L, Wang H-M, He F-M. Long-term outcomes of osteotome sinus floor elevation without bone grafts: a clinical retrospective study of 4-9 years. Clin Oral Implants Res. 2016;27(11):1392400. https://doi.org/10.1111/clr.12752.

35. Zill A, Precht C, Beck-Broichsitter B, Sehner S, Smeets R, Heiland M, et al. Implants inserted with graftless osteotome sinus floor elevation - a 5-year post-loading retrospective study. Eur J Oral Implantol. 2016;9(3):277-89.

36. Caban J, Fermergård R, Abtahi J. Long-term evaluation of osteotome sinus floor elevation and simultaneous placement of implants without bone grafts: 10-year radiographic and clinical follow-up. Clin Implant Dent Relat Res. 2017;19(6):1023-33. https://doi.org/10.1111/cid.12530.

37. Cheng $X$, Hu X, Wan S, Li X, Li Y, Deng F. Influence of lateral-medial sinus width on no-grafting inlay osteotome sinus augmentation outcomes. J Oral Maxillofac Surg Off J Am Assoc Oral Maxillofac Surg. 2017;75(8):1644-55. https://doi.org/10.1016/j.joms.2017.03.010.

38. Nedir R, Nurdin N, Abi Najm S, El Hage M, Bischof M. Short implants placed with or without grafting into atrophic sinuses: the 5-year results of a prospective randomized controlled study. Clin Oral Implants Res. 2017;28(7): 877-86. https://doi.org/10.1111/clr.12893.

39. Abi Najm S, Nurdin N, El Hage M, Bischof M, Nedir R. Osteotome sinus floor elevation without grafting: a 10-year clinical and cone-beam sinus assessment. Implant Dent. 2018;27(4):439-44. https://doi.org/10.1097/ID. 0000000000000793

40. Yang J, Xia T, Fang J, Shi B. Radiological changes associated with new bone formation following osteotome sinus floor elevation (OSFE): a retrospective study of 40 patients with 18-month follow-up. Med Sci Monit Int Med J Exp Clin Res. 2018;24:4641-8.

41. Nahlieli O, Boiangiu A, Abramson A, Aba M, Nahlieli D, Srouji S. Graftless sinus floor augmentation with an internal-port implant: long-term experience. Quintessence Int Berl Ger 1985. 2019:50:560-7.

42. Diserens V, Mericske E, Mericske-Stern R. Radiographic analysis of the transcrestal sinus floor elevation: short-term observations. Clin Implant Dent Relat Res. 2005;7(2):70-8. https://doi.org/10.1111/j.1708-8208.2005.tb00049.x.

43. Crespi $\mathrm{R}$, Capparè $\mathrm{P}$, Gherlone $\mathrm{E}$. Osteotome sinus floor elevation and simultaneous implant placement in grafted biomaterial sockets: 3 years of 
follow-up. J Periodontol. 2010;81(3):344-9. https://doi.org/10.1902/jop.2010. 090477.

44. Toffler M, Toscano N, Holtzclaw D. Osteotome-mediated sinus floor elevation using only platelet-rich fibrin: an early report on 110 patients. Implant Dent. 2010;19(5):447-56. https:/doi.org/10.1097/ID.0b013e3181f57288.

45. Aludden H, Mordenfeld A, Hallman M, Christensen A-E, Starch-Jensen T. Osteotome-mediated sinus floor elevation with or without a grafting material: a systematic review and meta-analysis of long-term studies ( $\geq 5$ years). Implant Dent. 2018;27(4):488-97. https://doi.org/10.1097/ID. 0000000000000798.

46. Narang S, Parihar AS, Narang A, Arora S, Katoch V, Bhatia V. Modified osteotome sinus floor elevation using combination platelet rich fibrin, bone graft materials, and immediate implant placement in the posterior maxilla. J Indian Soc Periodontol. 2015;19(4):462-5. https://doi.org/10.4103/0972-124 X.154188.

47. Brignardello-Petersen R. Osteotome sinus floor elevation without bone graft seems to result in high survival rates and small amount of bone loss after 10 years. J Am Dent Assoc 1939. 2018;149:e27.

48. Buser D, Weber HP, Lang NP. Tissue integration of non-submerged implants. 1-year results of a prospective study with 100 ITI hollow-cylinder and hollow-screw implants. Clin Oral Implants Res. 1990;1 (1):33-40. https:// doi.org/10.1034/j.1600-0501.1990.010105.x.

49. Albrektsson T, Zarb G, Worthington P, Eriksson AR. The long-term efficacy of currently used dental implants: a review and proposed criteria of success. Int J Oral Maxillofac Implants. 1986; (1):11-25.

50. Karthik K, Null S, Null S, Thangaswamy V. Evaluation of implant success: a review of past and present concepts. J Pharm Bioallied Sci. 2013;5(Suppl 1): S117-9. https://doi.org/10.4103/0975-7406.113310.

51. Raikar S, Talukdar P, Kumari S, Panda SK, Oommen VM, Prasad A. Factors affecting the survival rate of dental implants: a retrospective study. J Int Soc Prev Community Dent. 2017;7(6):351-5. https://doi.org/10.4103/jispcd. JISPCD_380_17.

52. Smeets R, Stadlinger B, Schwarz F, Beck-Broichsitter B, Jung O, Precht C, et al. Impact of dental implant surface modifications on osseointegration. Biomed Res Int. 2016;2016:6285620.

53. Tan WC, Lang NP, Zwahlen M, Pjetursson BE. A systematic review of the success of sinus floor elevation and survival of implants inserted in combination with sinus floor elevation. Part II: transalveolar technique. J Clin Periodontol. 2008;35(8 Suppl):241-54. https://doi.org/10.1111/j.1600-051X.2 008.01273.x

54. Del Fabbro M, Corbella S, Weinstein T, Ceresoli V, Taschieri S. Implant survival rates after osteotome-mediated maxillary sinus augmentation: a systematic review. Clin Implant Dent Relat Res. 2012;14(Suppl 1):e159-68. https://doi.org/10.1111/j.1708-8208.2011.00399.x.

55. Dental Supplement, Testori T, Panda S, Clauser T, Scaini R, Zuffetti F, et al. Short implants and platelet-rich fibrin for transcrestal sinus floor elevation: a prospective multicenter clinical study. J Biol Regul Homeost Agents. 2019; 33:121-35.

56. Barone A, Santini S, Sbordone L, Crespi R, Covani U. A clinical study of the outcomes and complications associated with maxillary sinus augmentation. Int J Oral Maxillofac Implants. 2006;21(1):81-5.

57. Cha H-S, Kim A, Nowzari H, Chang H-S, Ahn K-M. Simultaneous sinus lift and implant installation: prospective study of consecutive two hundred seventeen sinus lift and four hundred sixty-two implants. Clin Implant Dent Relat Res. 2014;16(3):337-47. https://doi.org/10.1111/cid.12012.

\section{Publisher's Note}

Springer Nature remains neutral with regard to jurisdictional claims in published maps and institutional affiliations.

\section{Submit your manuscript to a SpringerOpen ${ }^{\circ}$ journal and benefit from:}

- Convenient online submission

- Rigorous peer review

- Open access: articles freely available online

High visibility within the field

- Retaining the copyright to your article

Submit your next manuscript at $\boldsymbol{\nabla}$ springeropen.com 